\title{
Study on a new type of beverage bottle recycling device
}

\author{
MengyuanZhang ${ }^{1, a^{*}}$,Xiangdong You ${ }^{2, b}$,Cheng Dai ${ }^{3, c}$, YifeiWang \\ 4,d and JiawangCao ${ }^{5, \mathrm{e}}$ \\ ${ }^{1}$ Beijing University of Posts and Telecommunications, No.10,Xitucheng Road,Haidian District, \\ Beijing \\ a*myzhang@bupt.edu.cn, ${ }^{\text {b } y o u x i a n g d o n g @ 139 . c o m, ~}{ }^{\circ} 645398408 @ q q . c o m,{ }^{d}$ cynthia_fifi@bupt.edu.c \\ n, ${ }^{\mathrm{m}} \mathrm{mr}$ _wcao@163.com
}

Keywords:Beverage bottle recycling;Android;Photo printing; WeChat Photo

Abstract.This paper introduces a kind of method of printing photos and recycling used beverage bottles. Users upload photos by WeChat, then download the photo with the bottle-recycling device. After choosing the selection of 'Throw Bottles For Printing', the device can count the number of bottles threw in. Achieving the result of printing photos quickly and promoting environment protection. This device can increase the speed of printing, reduce the labor cost during photo print, promote work efficiency and advocate environment protection. This printing technology can be used for personalized photo or advertisement picture printing, etc., which contains good extensibility and application value.

\section{Introduction}

The phenomenon of throwing litter and used bottles about is common to see. People often use their phones to take photos, especially when they are travelling. When you take a lot of photos, there is a problem coming out: first, if you want to printing photos, you must go to special photo studio and usually in one or two days can you get you photos printed; second, although many scenic spots provide the service of "instant photo printing", the cost is always a little too high.

So it is a very significant thing to desgin a method of priting photos and recycling used beverage bottles and make it finished product, for not only can people print their photos quickly after throwing a certain number of bottles, but also this method can advocate protecting environment and provide people the photos they want to print.

This paper studies on the recycling of used bottles and the technology of photo printing, and on the basis of analysing related technologies, we studied and completed the technologies of bottle-recycling, uploading and downloading photos via WeChat, adding frame on photos and photo printing.

\section{The work flow of the bottle-recycling photo printer}

Work flow. As shown in the Fig.1, the method of photo printing designed by this paper provides the function of recycling used bottles, and after you throwing a certain number of bottles you can get the permission to print photos instantly. The whole work flow is listed below:

S1: Install a bottle-recycling photo printer.

S2: Start WeChat in your phone and follow the WeChatPublic Platform of the bottle-recycling photo printer, then you'll receive some instructions about the using of this device in your WeChat.

S3: Send the photo by WeChat and then get the identifying code.

S4: Input the identifying code in the device to download the photo, then the photo will be shown on the screen.

S5: You can choose to add frames in the printing options. There are several frames can be selected.

S6: Click the "OK" button after finishing setting printing options, the photo and the cost or the bottle numbers needed will be shown on the screen.

S7: For bottle-recycling, the photo will be printed automatically when the bottles are enough.

S8: For coins, the photo will be printed automatically when the coins are enough. 


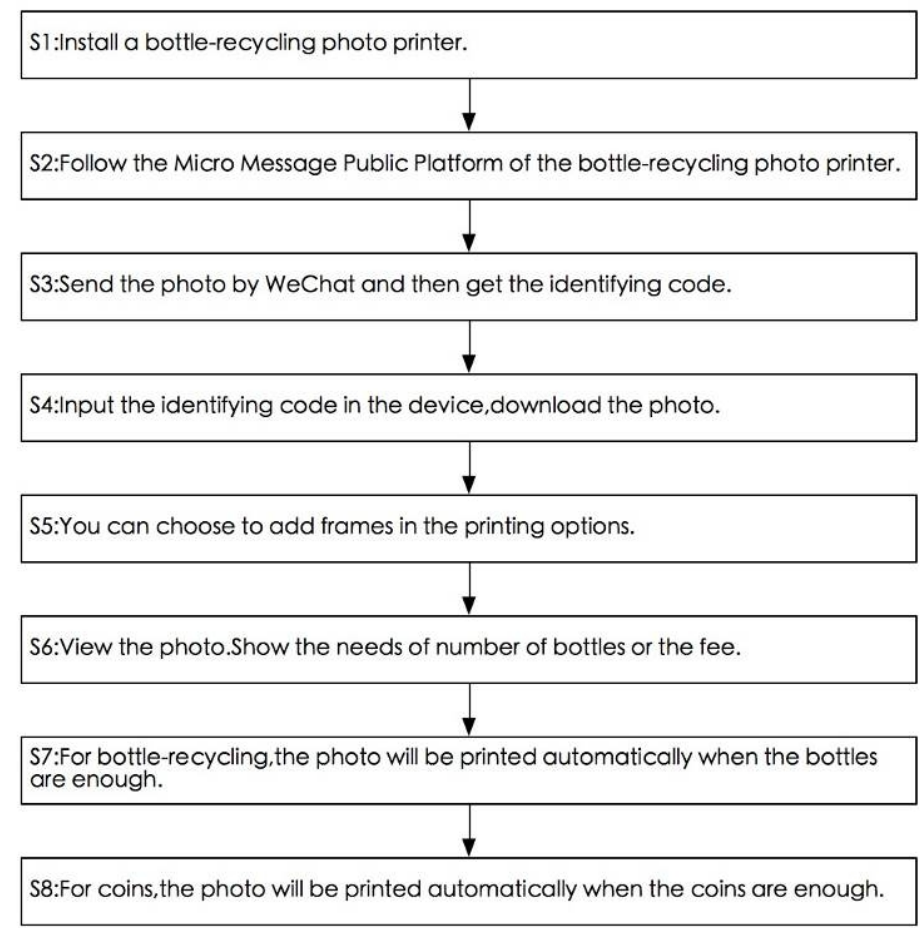

Fig.1 The work flow chart of the bottle-recycling device

The constitution of the bottle-recycling device. As shown as the Fig.2, the bottle-recycling device designed by this paper includes bottle-recycling module, control module, print module, coin-inserting module, show module and communication module.

The bottle-recycling module uses the single-chip microcomputer to realize the recognition of bottles, and counts by detecting the counting switch. The single chip microcomputer sends the counting result to the control module by serial communication. When the counting of the bottles are enough, the control module will allow photo printing.

The control module installsembedded system or PC system, and can operate system software of Linux, Android and Windows.

The control module can access the background server database by communication module to download the photo matched certain identifying code to the host and save it. The communication module includes WLAN, 3G, 4G and wired Ethernet module.

Beyond coin-operated payment, the device can also use e-payment to print, such as WeChat payment, Alipay payment and bankcard payment. If using the Alipay payment, you can scan the 2-dimensional bar code to pay money to specific Alipay account. After the payment successes the background server will inform the control module to permit printing.

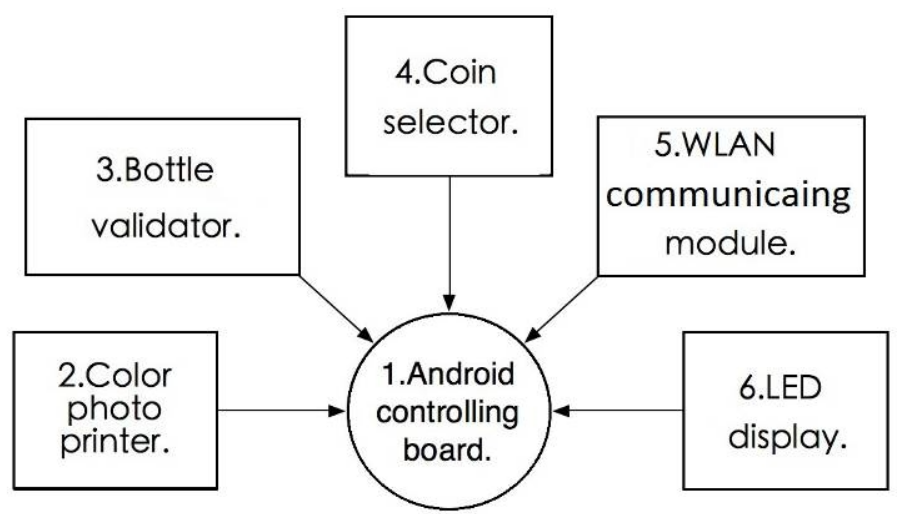

Fig.2 The constitution of the bottle-recycling device 


\section{The study and achieving of the main technology}

The uploading and downloading of photos. The specific process of the uploading of photos and the returning of identifying codes includes:

Users upload the photos they want to print to the bottle-recycling device by using personal WeChat account in their own mobile terminal, then the WeChat Public Platform send messages to the background server of the device, and the background sever database save the photos to the storage, meanwhile the sever send identifying code matched to the photo to the user by WeChat Public Platform.

Then users input the identifying code on the bottle-recycling device to request downloading from the background sever by the App and download the photo. When photo downloading finishes, it will be shown on the screen.

Adding frame on the photos. Described as following: the frames inserted in the software, when you click the image button of frames, the processing procedure of the software is that it will crop the photo to a certain size as the frame,then put the frame on the photo cropped. Fig.3 is a photo added frame.

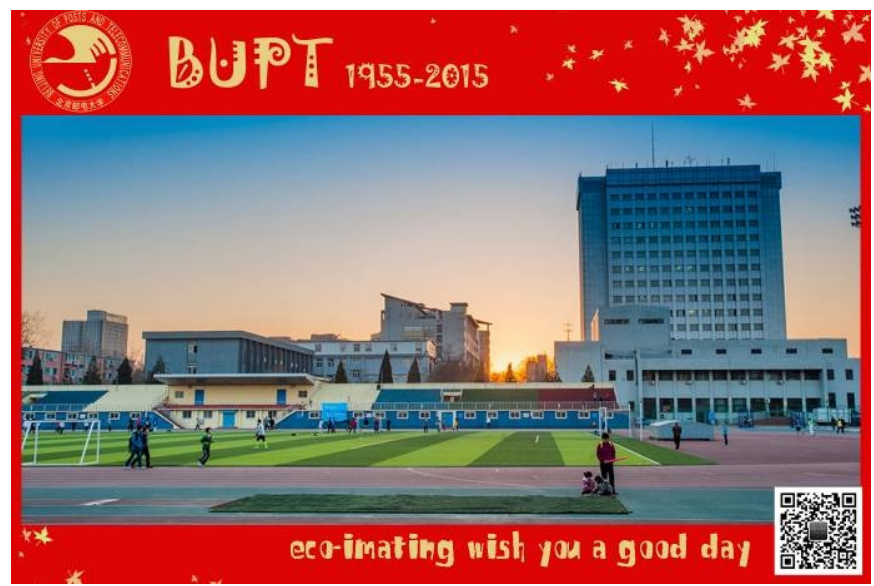

Fig.3A photo added frame

Technology for counting the bottles. The fundamental and interface for counting the bottles are stated asthe follow:

Bottle recycling module uses the SCM(Single-Chip Microcomputer) to realize the recognition of the bottle casting, and count by detecting the pulse count change of the switch. When the SCM detects a pulse, it will send the count results to the control module via a serial communication interface,the control module counts the number of bottles. When the bottles accumulated to a certain amount, the control module will allow printing photos.

The service of printing photos. The service of printing photos is provided by a miniPC and a photo printer. The model of the miniPC is $\mathrm{C} 1037 \mathrm{u}$ and the model of the photo printer is P110S. The miniPC installs Linux OS, which provides CUPS(Common Unix Printing System) to print. So Linux can provides printing service based on P110S after installing the drive software of P110S on CUPS.

The operating steps of printing is listed below:

Step1, Android OS send photos to Linux by HTTP.

Step2, Linux send photos to CUPS after receiving photos detected by scriplet, then CUPS drives P110S to print photos.

\section{The achievement of the application for the bottle-recycling device based on Android OS}

The GUI design of the App. The GUI design of the App includes the downloading, printing setting, bottle counting, photo printing interfaces and etc.. The Fig. 4 is the design layout of the UI interface. 


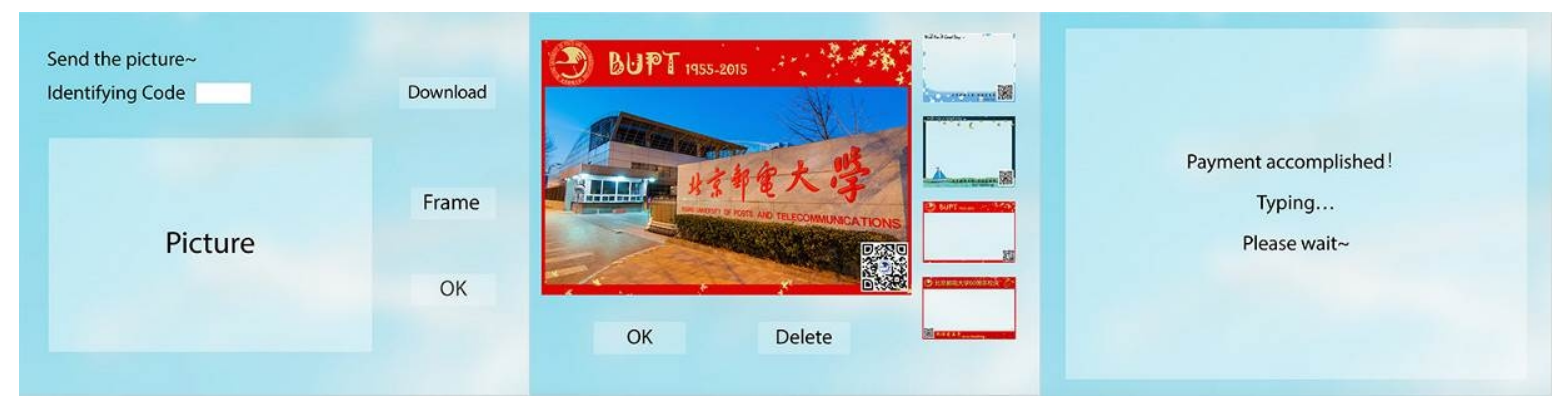

Fig.4The design layout of the UI interface

On the downloading interface, users can input identifying code and download with internet. It is shown as the Fig.5.On the printing setting interface, users can choose to add frames, cancel frames, and it is shown as Fig.6.On the bottle counting interface, the screen will show the numbers of bottles needed to throw in and the numbers of printing after users throw in certain numbers of bottles.

Users can print photos when they have permission. Photos printed is shown as Fig.7

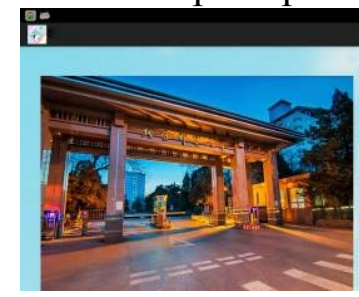

Fig.5 App interface

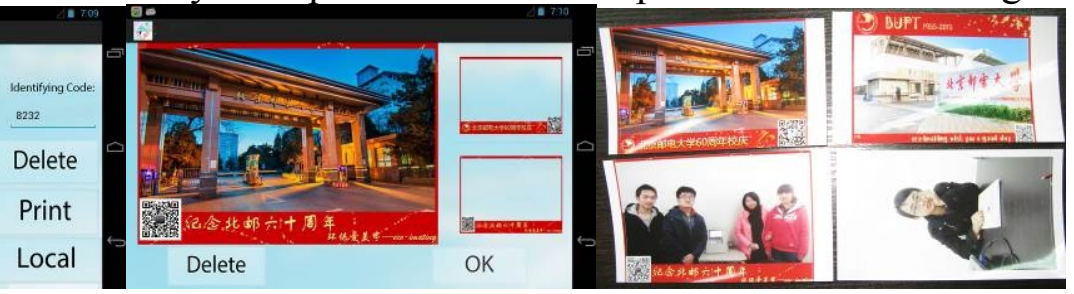

Fig.6 photo setting interface Fig.7 photos printed

\section{Conclusions}

In this paper,we design and realize a bottle-recycling photo printer based on Android.Device realizes the photos uploading and downloading,settings, counting the bottles and printing. In the subsequent uses it will increase the features like image rotation,vertical and horizontal printing, batch printing and snapshotting and etc.. It will give the smart phones and mobile Internet technology a better applicationin the industry, and improve efficiency further.

The results of this study have applied for a patent to the State Intellectual Property Office Of The P.R.C. The name of the patent is A Method and A Device of Bottle-recycling Photo Printer. The application number is 201510036590.8, and has received a notice of qualified preliminary examination, now in the patent disclosure and real-trial stage.

Technologies in this paper can be widely used in waste recycling, self photo printing, self studio, advertising photo printing, certificate photo printing and etc., with a wide range of promotional significance.

\section{Acknowledgement}

In this paper, the research was sponsored by the Research Innovation Fund for College Students of Beijing University of Posts and Telecommunications (Project No. 2014-49).

\section{References}

[1]ZeqiuLi,Weihong Li. The Research and Design of General Print System Based on Embedded Linux.SOFTWARE GUIDE,2011,10(4)

[2]FudongWang,Guangqing Shao. Multi-serial Port Communication Application for Single-chip Computer.CHINESE JOURNAL OF SCIENTIFIC INSTRUMENT, 2002,23(zl)

[3]Jian Chang. How to Implement an APP on Android which Communicates with the Server Asynchronously. Computer Programming Skills \& Maintenance, 2014, (10) 